\title{
Burnout in Greek Medical and Mental Health Care Workers
}

\author{
Ioanna Papathanasiou (Corresponding author) \\ Clinical Professor of Nursing, Nursing Department \\ Technological Educational Institute of Larissa, Greece
}

Tel: 30-241-068-4446_E-mail: iopapathanasiou@yahoo.gr,papathan@teilar.gr

\author{
Dimitrios Damigos \\ Assistant Professor, Medical School \\ University of Ioannina, Greece \\ E-mail: ddamig@cc.uoi.gr \\ Venetsanos Mavreas \\ Professor, Medical School \\ University of Ioannina, Greece \\ E-mail:vmavreas@cc.uoi.gr
}

Received: June 9, 2011 Accepted: June 29, 2011 doi:10.5539/gjhs.v3n2p206

\begin{abstract}
Burnout affects job performance ability. Studies show a higher level of burnout in health professionals. The purpose of this study was to investigate possible differences in professional burnout subscales between health workers in medical and mental health sector. The sample constituted of randomly selected 240 workers in medical health sector and 217 in mental health sector, aged 39.8 \pm 7.9 years old. Health workers from University and General Hospitals from all over Greece participated in the study. Maslach’s burnout inventory was used. SPSS 17.0 was used for statistics. The majority of health professionals were women. Over $50 \%$ of workers in mental health sector showed low emotional exhaustion and depersonalization, while one third of them gave a high personal accomplishment score. Mental health professionals showed statistically significantly lower scores in emotional exhaustion and depersonalization, in comparison with medical sector workers. Different working environments influence the development of health care workers' burnout.
\end{abstract}

Keywords: Burnout, Health professionals, Mental health

\section{Introduction}

Professional burnout has been defined as a physical and mental exhaustion syndrome. According to Maslach, burnout is the result of chronic stress (at the workplace) which has not been successfully dealt with (Maslach et al., 2001). It is characterized by emotional exhaustion depersonalization and a sense of a lack of personal achievement. It is found predominantly in caring and social professions (Angermeyer et al., 2006; Dickinson \&Wright, 2008). As consequences on patients and hospital function may be devastating, interest in the problem of burnout has grown over the past decades, in a setting of rapid job changes (Katsuki, 2005). Work pressure without support, new job requirements, role conflict, and role ambiguity are some of the stressors related to job burnout syndrome in clinical settings (Costantini et al., 1997). Mental health sector exhibits special features, mainly due to nature of the mental disease. It is argued that psychiatric nurses face unique job challenges compared to their counterparts who work in non-psychiatric wards (Yousefi \& Ghassemi, 2006). Differences in burnout levels within the mental health sector, depending on work place and subspecialties have also been investigated by other researchers (Currid, 2008).

The objective of the present study was to investigate possible differences in professional burnout subscales between health workers in medical and mental health sector. 


\section{Material and methods}

Maslach's burnout inventory was used in the research (Maslach et al., 1996). It consists of three groups of questions regarding the emotional exhaustion, the personal accomplishment and the depersonalization of workers. Questions 5, 10,11, 15, 22 refer to depersonalization, the 4, 7, 9, 12, 17, 18, 19, 21 to the personal achievement and the rest to the emotional exhaustion. Each person could give an answer in a Likert scale 0 to ( 0 never happens to me - 6 it happens every day).The sample constituted of randomly selected 240 workers in medical health sector and 217 in mental health sector, aged 39.8 \pm 7.9 years old. Health workers from University and General Hospitals from all over Greece participated in the study. Doctors, nurses and midwives were included. To the units of Athens and islands questionnaires were sent by post, while the distribution to the rest areas and their collection were carried out by research team. A preceding telephone contact with the directors of the departments took place, in order the suitable dates (working days) for the distribution and the collection of questionnaires to be determined. $76 \%$ of questionnaires (457 out of 600) were filled in properly and finally were included in the study.

\section{Statistics}

Descriptive statistics was initially generated for sample characteristics. To discriminate between burnout levels we used a table provided by Anagnostopoulos \& Papadatou (1992), referring to burnout components in health professionals in Greece, classifying burnout in low, moderate and high category (Table 1). Burnout scores are presented according to the above classification. T-test was used to compare means of burnout scores between medical and mental health sector. Statistics was processed with SPSS 17.0. Statistical significance was set at $\mathrm{p}=0.05$

\section{Results}

Mean age did not differ significantly between the two groups, being 40 years in medical health and 39 years in mental health sector. Regarding gender of the workers, men proportion was $25.5 \%$ in mental health sector and $21.5 \%$ in medical sector. Workers in medical sector had statistically more years (almost double) in the profession and in the certain department ( $\mathrm{t}=4,683, \mathrm{p}<0.001$ and $\mathrm{t}=4.040, \mathrm{p}<0.001$ respectively) (Table 2). Overall the professional burnout of health care workers is moderate. Mental health sector workers were found to have a marginally low emotional exhaustion (18.46), whereas medical sector had a moderate score (26, 41), a difference proved statistically significant. Personal achievement scores were close to upper limit of moderate subscale, 36.70 and 37.28 for medical and mental sector respectively. Workers in medical sector have significantly higher mean scores of depersonalization(9.81), being close to upper limit of moderate subscale, while the 6.73 value of mental sector place it at the lower limit of the same subscale, a difference also statistically significant (Table 3). Over $50 \%$ of workers in mental health sector showed low emotional exhaustion and depersonalization, while one third of them gave a high personal achievement score (table 4).

\section{Discussion}

According to the findings of the present study, burnout level is lower in mental health staff in comparison to medical staff and is considered rather moderate. Burnout symptoms have been recognized in psychiatrists and psychologists since 1980's (Farber, 1985) and scientific interest has increased over the past decade, as mental staff burnout could result even in disease relapse (Katsuki et al., 2005).Regarding burnout prevalence in mental health care workers, data differs depending on the professional group, with nurses being highly vulnerable (Faber, 1985; Foxall et al., 1990). Farber showed that moderate burnout was present in 36\% of doctors working with mentally disabled individuals, while 6,3\% exhibited high levels of burnout. Psychologists and social workers were particularly vulnerable, while burnout was present in $43 \%$ of psychiatrists (Faber, 1985). Although nurses in Intensive Care Units and medical wards more often face stressful situations burnout prevalence isn't necessarily higher in this group (Kelly et al., 1985; Sahraian et al., 2008; Sarafis et al., 2008). Family status, social support, personality, support from colleagues and supervisors play important role in the onset of burnout. Moreover, patients' characteristics, such violent behaviour and suicide ideation, staff's non realistic expectations regarding mental disease recovery and health worker-patient interaction are of vital importance in developing burnout (Melchior et al., 1997; Moustaka et al., 2009). A recent study focusing on hospital nurses revealed that nurses of psychiatry ward showed significantly higher levels of emotional exhaustion and depersonalization in comparison with nurses working in other wards (Sahraian et al., 2008). In another study, regarding Iranian mental health care workers it was found that $45.6 \%$ of the sample had job burnout at a high level (Ashtari et al., 2009). Emotional exhaustion and depersonalization was the prominent features of burnout. It is noticed that doctors had refused participation in that study. Kee et al. (2002) also identified emotional exhaustion and depersonalization as major contributors of burnout. 
These findings are not supported by ours, since the participants had overall low levels of emotional exhaustion and depersonalization, significantly lower than medical care staff. Qualitative and quantitative characteristics of the sample could account for reduced levels of burnout. The sample was not homogeneous, consisting of health care workers of various specialties, working under quite different conditions. In Greece, internists and surgeons serve in emergency departments, leaving an accessory role for other specialties, while there are no specialized emergency or a separate psychiatric emergency unit. As a result, a major work load contributor is probably removed. On the other hand, lack of involvement in lifesaving procedures may result in a perception of low personal accomplishment and enhance burnout. Motivation upon entering the profession, personal style and culture interact to enhance or avert burnout (Moustaka et al., 2010; Noula et al., 2010). Other sources of satisfaction should also be considered, such the reward system which could be more effective in mental sector, as there is more time available, in comparison with other departments, where the combination of staff shortage and intense work is a persistent feature (Malliarou et al., 2010; Tountas \& Karnaki, 2002). Moreover, as nurses usually exhibit high percentages of burnout, the heterogeneity of the sample in this study may skew the results.

A next step should include study of demographic characteristics and work environment, in order to determine the factors that could account for the rather low percentage of burnout among mental health workers in the present study. Homogenous samples could reveal the particular vulnerable groups and provide the appropriate explanation. In any case, a careful consideration of all possible factors affecting health care workers behaviour is necessary.

\section{References}

Anagnostopoulos, F. \& Papadatou, D. (1992). Reliability and validity of the Maslach burnout inventory to a population of nurses. Journal of Psychological Issues, 5, 183-202. (published in Greek).

Angermeyer, M. C., Bull, N., Bernert, S., Dietrich, S., \& Kop, A. (2006). Burnout of caregivers: a comparison between partners of psychiatric patients and nurses. Arch Psychiatr Nurs., 20, 158-65. http://dx.doi.org/10.1016/j.apnu.2005.12.004

Ashtari, Z., Farhady, Y., \& Khodaee, M. R. (2009). Relationship between job burnout and work performance in a sample of Iranian mental health staff. Afr J Psychiatry (Johannesbg), 12, 71-4. [Online] Available: http://www.ajop.co.za/Journals/February2009/Ajp_13.pdf

Costantini, A., Solano, L., Di Napoli, R., \& Bosco, A. (1997). Relationship between hardiness and risk of burnout in a sample of 92 nurses working in oncology and AIDS wards. Psychother Psychosom, 66, 78-82.

Currid, T. J. (2008). The lived experience and meaning of stress in acute mental health nurses. Br J Nurs., 17, 880-884.

Dickinson, T. \& Wright, K. M. (2008). Stress and burnout in forensic mental health nursing: a literature review. $\mathrm{Br}$ J Nurs., 17, 82-7.

Farber, B. A. (1985). Clinical psychologists' perceptions of psychotherapeutic work. The Clinical Psychologist, 38, 10-13.

Foxall, M. J., Zimmerman, L., Standley, R., \& Bené, B. (1990). A comparison of frequency and sources of nursing job stress perceived by intensive care, hospice and medical-surgical nurses. $J$ Adv Nurs., 15, 577-84. http://dx.doi.org/10.1111/j.1365-2648.1990.tb01857.x

Katsuki, F., Goto, M., \& Someya, T. (2005). A study of emotional attitude of psychiatric nurses: reliability and validity of the Nurse Attitude Scale. Int $J$ Ment Health Nurs, 14, 265-70. http://dx.doi.org/10.1111/j.1440-0979.2005.00391.x

Kee, A. J., Don Johnson, \& Portia Hunt. (2002). Burnout and Social Support in Rural Mental Health Counselors. Journal of Rural Community Psychology, E5 (1). [Online] Available: http://www.marshall.edu/jrcp/sp2002/Kee.htm

Kelly, J. G., Cross, D. G. (1985). Stress, coping behaviors, and recommendations for intensive care and medical surgical ward registered nurses. Res Nurs Health, 8, 321-8. http://dx.doi.org/10.1002/nur.4770080404

Maslach, C., Jackson, S. E., \& Leiter, M. P. (1996). Maslach burnout inventory manual. Palo Alto, CA: Consulting Psychologists Press.

Malliarou, M., Sarafis, P., Moustaka, E., Kouvela, T., \& Constantinidis, T. C. (2010). Greek Registered Nurses’ Job Satisfaction in Relation to Work-Related Stress. A Study on Army and Civilian Rns. Global Journal of Health Science, 2 (1), 44-60. [Online] Available: http://www.ccsenet.org/journal/index.php/gjhs/article/view/4924/4541 
Maslach, C., Schaufeli, W., \& Leiter, M. P. (2001). Job burnout. Annu Rev Psychol, 52, 397-422. http://dx.doi.org/10.1146/annurev.psych.52.1.397

Melchior, M. E., Bours, G. J., Schmitz, P., \& Wittich, Y. (1997). Burnout in psychiatric nursing: a meta-analysis of related variables. $J$ Psychiatr Ment Health Nurs, 4, 193-201. http://dx.doi.org/10.1046/j.1365-2850.1997.00057.x

Moustaka, E., Malliarou, M., Sarafis, P., Constantinidis, T. K., \& Manolidou, Z. (2009). Burnout in Nursing Personnel in a Regional University Hospital. Balkan Military Medical Review, 12(1), 1-7. [Online] Available: http://www.geetha.mil.gr/media/BMMR/2009/BMMR_12_No_1_2009.pdf

Moustaka, E., Antoniadou, F., Malliarou, M., Zantzos, I., Kiriaki, C., \& Constantinidis, T. C. (2010). Research in occupational stress among nursing staff - a comparative study in capital and regional hospitals. Hellenic journal of

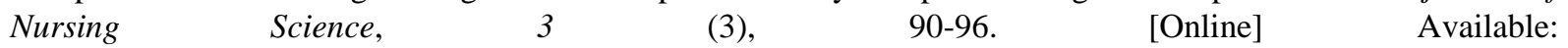
http://magazine.enne.gr/wp-content/uploads/2010/11/TOMOS3TEFXOS3_AGGLIKO-dragged3.pdf

Noula, M., Mouchaki, S., Argyropoulou, D., Yfani, E., Kyriakidou, B., Tsiriga, S., \& Gesouli, E. (2010). Nurses' professional burnout in Athens and province areas. Nurses' Interscientific Health Care, 2 (2), 99-103. (published in Greek). [Online] Available: http://www.inhealthcare.gr/article/en/i-epaggelmatiki-eksouthenosi-nosileuton-se-nosokomeia-ton-athinon-kai-ti s-eparxias

Sahraian, A., Fazelzadeh, A., Mehdizadeh, A. R., \& Toobaee, S. H. (2008). Burnout in hospital nurses: a comparison of internal, surgery, psychiatry and burns wards. Int Nurs Rev, 55, 62-7. [Online] Available: http://www.carloshaya.net/biblioteca/enfer2008/burnout.pdf http://dx.doi.org/10.1111/j.1466-7657.2007.00582.x

Sarafis, P., Stamataki, P., \& Malliarou, M. (2008). Burnout of ICU nursing personnel. Clinical Annals, 31 (1), 29-37. (published in Greek).

Tountas, Y. \& Karnaki, P. (2002). Reforming the Reform-The Greek National Health System in Transition. Health Policy, 62, 15-29. [Online] Available: http://www.sciencedirect.com/science/article/B6V8X-44HXHP1-1/2/f7cac4515800814e06218d336faff9f4 http://dx.doi.org/10.1016/S0168-8510(01)00217-2

Yousefy, A. R. \& Ghassemi, G. R. (2006). Job burnout in psychiatric and medical nurses in Isfahan, Islamic Republic of Iran. East Mediterr Health J., 12 (5), 662-9. [Online] Available: http://www.emro.who.int/publications/emhj/1205/PDF/Article21.pdf

Table 1. Cut-off values for low, moderate and high levels of professional burnout

\begin{tabular}{|l|c|c|c|}
\hline Subscale & Low & Moderate & High \\
\hline Emotional exhaustion & $\leq 20$ & $21-30$ & $\geq 31$ \\
\hline $\begin{array}{l}\text { Personal } \\
\text { accomplishment }\end{array}$ & $\geq 42$ & $41-36$ & $\leq 35$ \\
\hline Depersonalization & $\leq 5$ & $6-10$ & $\geq 11$ \\
\hline
\end{tabular}

Table 2. Descriptive statistical results and Student's $\mathrm{t}$ - test for mean differences

\begin{tabular}{|l|c|c|c|c|c|c|}
\hline Demographic features & \multicolumn{2}{|c|}{ Medical sector } & \multicolumn{2}{c|}{ Mental health sector } & \multicolumn{2}{c|}{$\begin{array}{c}\text { Control for mean } \\
\text { Difference }\end{array}$} \\
\hline & Mean & SD & Mean & SD & $t$ & $\mathrm{P}$ \\
\hline Birth year & 1969 & 7.95 & 1970 & 8.19 & -0.435 & 0.664 \\
\hline Number of children & 1.29 & 1.13 & 1.20 & 1.11 & 0.804 & 0.422 \\
\hline Years in profession & 18.34 & 7.65 & 9.31 & 7.50 & 4.683 & 0.000 \\
\hline Years in department & 10.52 & 7.65 & 4.07 & 4.27 & 4.040 & 0.000 \\
\hline
\end{tabular}


Table 3. Cut-off values for low, moderate high levels of professional burnout and mean sample values

\begin{tabular}{|c|c|c|c|c|c|}
\hline & Low & Moderate & High & $\mathbf{t}$ & $\mathbf{p}$ \\
\hline Emotional exhaustion & $\leq \mathbf{2 0}$ & $21-30$ & $\geq 31$ & \multirow[t]{3}{*}{7.117} & \multirow[t]{3}{*}{0.000} \\
\hline Medical sector & & 26.41 & & & \\
\hline Mental Health sector & 18.46 & & & & \\
\hline Personal accomplishment & $\geq 42$ & $41-36$ & $\leq 35$ & \multirow[t]{3}{*}{-0.990} & \multirow[t]{3}{*}{0.323} \\
\hline Medical sector & & 36.70 & & & \\
\hline Mental Health sector & & 37.28 & & & \\
\hline Depersonalization & $\leq 5$ & 6-10 & $\geq 11$ & \multirow[t]{3}{*}{5.040} & \multirow[t]{3}{*}{0.000} \\
\hline Medical sector & & 9.81 & & & \\
\hline Mental Health sector & & 6.73 & & & \\
\hline
\end{tabular}

Table 4. Number of Workers with low, moderate and high levels of professional burnout

\begin{tabular}{|c|c|c|c|c|c|c|}
\hline \multirow{2}{*}{} & \multicolumn{3}{|c|}{ Medical sector } & \multicolumn{3}{c|}{ Mental Health sector } \\
\cline { 2 - 7 } & Low & Moderate & High & Low & Moderate & High \\
\hline Emotional Exhaustion & 89 & 58 & 93 & 135 & 51 & 28 \\
& $(37.1 \%)$ & $(24.2 \%)$ & $(38.8 \%)$ & $(63.1 \%)$ & $(23.8 \%)$ & $(13.1 \%)$ \\
\hline Personal Achievement & 61 & 83 & 96 & 65 & 85 & 64 \\
& $(25.4 \%)$ & $(34.6 \%)$ & $(40.0 \%)$ & $(30.4 \%)$ & $(39.7 \%)$ & $(29.9 \%)$ \\
\hline Depersonalization & 73 & 75 & 92 & 114 & 44 & 56 \\
& $(30.4 \%)$ & $(31.3 \%)$ & $(38.3 \%)$ & $(53.3 \%)$ & $(20.6 \%)$ & $(26.2 \%)$ \\
\hline
\end{tabular}

*percentages in the whole sample 